\title{
Erratum to: In vitro comparison of different carrier materials with rat bone marrow MSCs
}

\author{
M. Gierloff • T. Nitsche $\cdot$ S. Adam-Klages $\cdot$ K. Liebs $\cdot$ \\ J. Hedderich • V. Gassling • J. Wiltfang $\cdot$ D. Kabelitz • \\ Y. Açil
}

Published online: 22 June 2013

(C) Springer-Verlag Berlin Heidelberg 2013

Erratum to: Clin Oral Invest

DOI 10.1007/s00784-013-0956-9

The original version of this article inadvertently contained a mistake. The family name of the last author was misspelled. It should be Y. Açil.

The online version of the original article can be found at http://dx.doi.org/ 10.1007/s00784-013-0956-9.

M. Gierloff $(\bowtie) \cdot$ T. Nitsche $\cdot$ K. Liebs $\cdot$ V. Gassling $\cdot$

J. Wiltfang $\cdot$ Y. Açil

Department of Oral and Maxillofacial Surgery,

Christian-Albrechts-University Kiel,

Arnold-Heller-Strasse 16, 24105 Kiel, Germany

e-mail: gierloff@mkg.uni-kiel.de

S. Adam-Klages $\cdot$ D. Kabelitz

Department of Immunology, Christian-Albrechts-University Kiel,

Arnold-Heller-Strasse 3, $24105 \mathrm{Kiel}$, Germany

J. Hedderich

Institute of Medical Informatics and Statistics,

Christian-Albrechts-University Kiel,

Arnold-Heller-Strasse 3, 24105 Kiel, Germany 